\title{
ESTABILIDAD DE CHICHEME PROCEDENTE DEL DEPARTAMENTO DE CÓRDOBA COLOMBIA
}

\section{STABILITY OF CHICHEME FROM THE DEPARTMENT OF CORDOBA (COLOMBIA)}

\begin{abstract}
Diofanor Acevedo ${ }^{1}$, Yenis Pastrana ${ }^{2}$, Alba Durango $^{3}$
${ }^{1}$ Ingeniero de Alimentos, Ph.D. Ingeniería de Alimentos. Universidad de Cartagena, Grupo de Investigación Nutrición, Salud y Calidad Alimentaria (NUSCA), Avenida El Consulado, Calle 30 No, 48-152, Cartagena, Bolívar Colombia, e-mail: dacevedoc@unicartagena.edu.co; ${ }^{2}$ Ingeniera de Alimentos, M.Sc. en Ciencias Agroalimentarias. Universidad de Córdoba, Facultad de Ingeniería, Departamento de Ingeniería de Alimentos, km 12 vía Cereté Ciénaga de Oro sede de Berástegui, Córdoba, email: yipastrana@correo.unicordoba.edu.co; ${ }^{3}$ Bacteriologa, Ph.D. Ciencia y Tecnología de Alimentos. Universidad de Córdoba, Facultad de Ingeniería, Departamento de Ingeniería de Alimentos, km 12 vía Cereté Ciénaga de Oro sede de Berástegui, Córdoba, e-mail: adurango@correo.unicordoba.edu.co.
\end{abstract}

Rev. U.D.C.A Act. \& Div. Cient. 19(2): 395-402, Julio-Diciembre, 2016

RESUMEN

Los productos autóctonos, se consideran exóticos por sus materias primas y técnicas particulares de producción y para hacerlos más competitivos en el mercado nacional e internacional, se deben encontrar estrategias de conservación, que prolonguen su vida útil. El propósito de esta investigación fue evaluar la estabilidad química, microbiológica y sensorial del chicheme, elaborado tradicionalmente en el municipio de Ciénaga de Oro, Córdoba Colombia. Se preparó el chicheme con la adición de Syzygium aromaticum (clavo) y Cinnamomum verum (canela), en concentraciones de 730ppm, para el tratamiento T1; 1460ppm, para T2 y 2190ppm, para T3 comparada con un control. También, se efectuó un análisis químico, como pH, acidez y ${ }^{\circ}$ Brix; además, se realizó un recuento de psicrotróficos, coliformes totales y fecales, bacterias ácido lácticas, Bacilluscereus, Staphylococcus aureus y mohos y levadura. El producto fue envasado en frascos de plástico PET y vidrio de $500 \mathrm{~mL}$ y almacenados a $4^{\circ} \mathrm{C}$, durante 7 días. Los resultados, se sometieron a un análisis de varianza y una prueba de comparación de Tukey, utilizando el paquete estadístico SAS Windows Versión 8. El chicheme adicionado con la concentración más alta de canela y clavo y en envases de vidrio, logró un mayor tiempo de almacenamiento y un menor recuento de mohos y de levaduras. Por el contrario, la bebida colocada en envases de plástico tuvo mayor conteo de microorganismos, debido a que el PET es más poroso que el vidrio.

Palabras clave: Conservantes naturales, Syzygium aromaticum, Cinnamomum verum.

\section{SUMMARY}

Local products are considered exotic due to their ingredients and the particular production technics; to make them more competitive in the national and international market, conservation strategies that prolong its shelf life must be found. The purpose of this research was to evaluate the chemical, microbiological and sensory stability of "chicheme" prepared traditionally in the municipality of Cienaga del Oro, Cordoba, Colombia. Chicheme was elaborated with the addition of clove Syzygium aromaticum and cinnamon Cinnamomum verumin at concentrations of 730ppm for treatment T1, 1460ppm for T2 and for2190ppm T3 compared with a control. Furthermore, a chemical analysis was performed, determining $\mathrm{pH}$, acidity and ${ }^{\circ}$ Brix; also a recount of psicrotrofics, total and fecal coliforms, acidic lactic bacteria, Bacillus cereus, Staphylococcus aureus, molds and yeast was carried out. The product was kept in both plastic, PET, and glass jars of $500 \mathrm{~mL}$ capacity and stored at $4^{\circ} \mathrm{C}$ for 7 days. The results were subjected to a variance analysis and a Tukey comparison test using the statistical package SAS Windows Version 8. Chicheme added with the highest concentration of cinnamon and cloves and stored in glass containers, showed a longer storage time and a lower count of molds and yeasts. On the other hand, the product placed in plastic containers presented a greater count of microorganisms, probably because PET is more porous than glass.

Keywords: Natural preservatives, Syzygium aromaticum, Cinnamomum verum. 


\section{INTRODUCCIÓN}

El chicheme es una bebida láctea pasterizada y se clasifica según su contenido de materia grasa total. Para su preparación, primero se calcula la cantidad de agua empleada; seguido, se adiciona una mezcla de canela y clavo de olor; inmediatamente, se le agrega el maíz y se lleva a cocción por ebullición, con el $80 \%$ del contenido de agua en un recipiente metálico hasta ablandar el cereal, aproximadamente, durante $65 \mathrm{~min}$; luego, se licua el resto del agua con la leche en polvo y se adiciona el azúcar y el cloruro de sodio; al instante, se realiza una segunda cocción con todos los ingredientes anteriores hasta ebullición, con agitación constante; más tarde, se somete a enfriamiento, a temperaturas de $20-25^{\circ} \mathrm{C}$ y se envasa en recipientes de plástico de polipropileno. Esta bebida, actualmente, ha presentado problemas de salud en la población de consumo, debido a que se somete a un proceso térmico inadecuado y envasado inapropiado.

Los brotes de enfermedades transmitidas por los alimentos son de extrema importancia para la salud pública (Toyofuku, 2014; Rocourt, 2014; Shan et al. 2014; Young et al. 2014). Debido a esto, se presenta la necesidad de acoger nuevas metodologías en higiene y seguridad, para reducir o eliminar agentes patógenos en los alimentos, que afecten la salud de los consumidores y disminuyan la calidad de los mismos (Nsoesie et al. 2014; Kim et al. 2015). Una metodología eficaz consiste en la aplicación de especias naturales en alimentos, como conservantes, como es el caso de las propiedades antimicrobianas del propóleos (Alzate et al. 2011; Rodríguez, 2011; Vargas et al. 2013). Investigaciones realizadas por Mirzoeva et al. (1997) reportaron que algunos de los compuestos en los propóleos, como la quercetina y la narangenina, provocan un incremento en la permeabilidad, reduciendo el potencial de la membrana bacteriana, lo que conduce a disminuir la resistencia de las bacterias frente a agentes antimicrobianos. Existen investigaciones con pimienta negra, anís, nuez moscada, canela y clavo de olor, entre otros, siendo los dos últimos, los más empleados en diferentes bebidas, como el chicheme y la avena Sinuana (Pastrana et al. 2015); sin embargo, su utilización comercial es mínima (Arora \& Kaur, 1999).

Existen numerosos compuestos en los aceites esenciales (AE) de especias y de plantas aromáticas, entre los que se encuentran fenoles, terpenoides y aldehídos, capaces de controlar el desarrollo de algunos microorganismos (Acevedo et al. 2013a; 2013b). El clavo (Syzygium aromaticum) y la canela (Cinnamomum verum) usados en la industria de alimentos por su aroma y sabor atractivo, contienen aldehído cinámico y eugenol, compuestos estudiados por sus propiedades antimicrobianas (Gende et al. 2010).
El aceite esencial de clavo tiene un efecto control sobre la microbiota nativa y sobre los microorganismos patógenos, tales como E. coli O157: H7 (Goñi et al. 2016). Los principales constituyentes de aroma de Syzygium aromaticum fueron eugenol y acetato de eugenilo, donde el eugenol tiene actividad antifúngica. Aceites esenciales han sido analizados, encontrando cerca de 18 compuestos; estos componentes del clavo de olor, se han probado para propiedades antioxidantes en el ensayo de sustancias reactivas al ácido tiobarbitúrico (TBARS). Poco se sabe sobre el grado en que los aceites esenciales de especias pueden contribuir a la actividad antioxidante, aunque han sido ampliamente analizados para su uso en la medicina, propiedades culinarias y como antimicrobianos (Özcan \& Arslan, 2011). La capacidad antioxidante puede estar relacionado con la presencia de carvacrol, timol y eugenol, en los aceites esenciales; sin embargo, se necesitan más investigaciones sobre la determinación de la correlación entre la capacidad antioxidante y la composición química de los aceites esenciales.

La presencia de compuestos fenólicos y volátiles en aceite esencial de canela proporcionan el sabor y el aroma de esta especie; tales características han llevado a su amplia aplicación en la industria de alimentos. Las actividades biológicas de sus principales compuestos, como el cinamaldehído, el linalor y el alcanfor permiten su aplicación en alimentos, por su poder antioxidante, bactericida y antifúngico (CardosoUgarte et al. 2016).

Los productos autóctonos del Caribe colombiano se consideran exóticos, por sus materias primas y técnicas particulares de producción y para hacerlos más competitivos en el mercado nacional e internacional, se deben encontrar diversas estrategias de conservación, puesto que, en la actualidad, no se utiliza ninguna clase de conservantes en la elaboración de estos productos, propios de la región.

Aparte que se desconocen las propiedades conservantes de estos compuestos, también se comercializan en envases inadecuados, sin mantener la cadena de frío del alimento, para evitar que sufra alteraciones microbianas, conduciendo a la fermentación y afectando su vida útil. Esta investigación tuvo como finalidad evaluar la estabilidad química, microbiológica y sensorial del chicheme, una bebida autóctona del departamento de Córdoba, Colombia, con la adición de clavo Syzygium aromaticum y canela Cinnamomum verum.

\section{MATERIALES Y MÉTODOS}

Proceso de elaboración de chicheme. En la tabla 1, se muestra la formulación para la preparación de chicheme, que se elaboró en los Laboratorios de la Universidad de Córdoba, teniendo en cuenta el proceso de elaboración por las famiempresas del Municipio de Ciénega de Oro, Magdalena. 
En primer lugar, se determinó la cantidad de agua, como base de cálculo para la elaboración de la bebida; se realizaron tres formulaciones con adición de clavo y de canela y un control sin adición; todos los tratamientos se llevaron a cabo por triplicado. Luego, se pesaron los insumos y se adicionó una mezcla de clavo y de canela, en proporciones de730ppm, al tratamientoT1; 1460ppm, alT2 y 2190ppm, al T3. Posteriormente, se llevó a cocción las especias y el maíz trillado durante $65 \mathrm{~min}$, en un recipiente de metal, hasta producir el ablandamiento del maíz, con agitación constante, previniendo la formación de partículas aglomeradas; después, se licuó la leche en polvo, el agua, el azúcar y el cloruro de sodio. Este tipo de leche se seleccionó, debido a que es el que se utiliza en la bebida tradicional de Ciénega de Oro, Magdalena, además le aporta al producto final un sabor y aroma agradable. Más tarde, se mezclaron las dos preparaciones y se realizó una segunda cocción, hasta ebullición con agitación; una vez terminado el proceso, se enfrío, hasta llegar a temperaturas de 20 a $25^{\circ} \mathrm{C}$; finalmente, se envasaron 10 bebidas por cada tratamiento y se depositaron en envases de plástico y de vidrio con tapa estriada a rosca de $500 \mathrm{~mL}$ de capacidad; al final, las muestras fueron almacenadas a $4^{\circ} \mathrm{C}$, durante siete días.

Análisis químicos. Se realizaron análisis químicos, como pH, mediante método potenciométrico, según AOAC 981.12/90 y acidez por titulación, según AOAC 942.15/90 adaptado. La medida de $\mathrm{pH}$ es muy útil para medir la acidez o la basicidad de la bebida, garantizando que el producto final se encuentre exento de microorganismos; además, el $\mathrm{pH}$ influye de forma directa en el control aplicado, para evitar la activación de bacterias, debido a que es importante en la conservación de alimentos; asimismo, se analizaron los ${ }^{\circ}$ Brix por método refractométrico, según AOAC 932.12/90. En general, estos análisis son importantes practicarlos, debido a que son pruebas de control de calidad.
Análisis microbiológico. Durante el tiempo de almacenamiento, se realizaron conteos microbiológicos, estudiados a los $0,4,7,12$ y 15 días de almacenamiento, por triplicado de: psicotróficos, bacterias ácido lácticas BAL, mohos y levaduras, coliformes totales, Escherichia coli, Staphylococcus aureus y Bacillus cereus, de acuerdo a la metodología propuesta por las Normas Técnicas Colombianas, NTC 2160 de 2006, NTC 4458 de 2007 y NTC 4779 de 2007.

Análisis sensorial. Se realizaron pruebas sensoriales, como sabor, color, olor e impresión global (IG); las muestras denominadas blanco y los tratamientos 1,2 y 3 fueron sometidas a una prueba de aceptación-preferencia, mediante una escala hedónica de 9 puntos, donde 1 representa la apreciación "Me disgusta extremadamente y 9 "Me gusta extremadamente"; la prueba se practicó con 30 panelistas sin experiencia, que consumen estos productos regularmente. Las bebidas fueron evaluadas durante los 0, 4, 7 y 15 días de almacenamiento. El lugar donde se practicaron las muestras cumple los requisitos requeridos por la ISO 8589 de 1988, en relación a cabinas individuales de color blanco, al igual que las paredes y muebles, lugar libre de ruidos, de olores extraños y distracciones, temperatura alrededor de $20^{\circ} \mathrm{C}$, iluminación con tubos fluorescentes en las cabinas y techos, entre otras.

Análisis estadístico. A los datos fisicoquímicos y sensoriales que se obtuvieron de las formulaciones realizadas por triplicado, se les aplicó un diseño experimental en parcelas subdivididas, donde se designó a la parcela, el día; la parcela dividida, los empaques y la parcela subdividida, los porcentajes de las concentraciones de clavo de olor y canela. Los resultados, se sometieron a un análisis de varianza y una prueba de comparación de Tukey, a un nivel de significancia del $5 \%(p \leq 0,05)$, utilizando el paquete estadístico SAS Windows Versión 8. Los análisis microbiológicos, se analizaron mediante estadística descriptiva.

Tabla 1. Formulación para chicheme, porcentaje (\%p/v).

\begin{tabular}{|c|c|c|c|c|}
\hline Materia prima & Control & T1 & T2 & T3 \\
\hline Agua & 61,99 & 61,92 & 61,84 & 61,77 \\
\hline Leche en polvo & 11 & 11 & 11 & 11 \\
\hline Maíz trillado & 15 & 15 & 15 & 15 \\
\hline Azúcar & 12 & 12 & 12 & 12 \\
\hline Clavo y Canela \%v/v & 0 & 0,073 & 0,146 & 0,219 \\
\hline Sal & 0,01 & 0,01 & 0,01 & 0,01 \\
\hline
\end{tabular}




\section{RESULTADOS Y DISCUSIÓN}

Análisis químicos. La tabla 2 muestra las características químicas de los diversos tratamientos para la bebida chicheme, envasada en empaques de plástico y vidrio, durante siete días de almacenamiento refrigerado. También, se observa la prueba de diferencias mínimas significativas (DMS), realizada para notar diferencias entre las medias del $\mathrm{pH}$, acidez $^{\circ}$ Brix, con respecto al tipo de envase. Al analizar las variables químicas, haciendo énfasis en el tipo de envasado, se evidenció que el $\mathrm{pH}$ de la muestra control en el día 4 y 7 no mostraron diferencias significativas en el envase de plástico y vidrio; sin embargo, el tratamiento 1 solamente tuvo diferencias en el día 0 . Por su parte, el tratamiento 2 mostró diferencias durante todos los días analizados en el envase de plástico en relación al de vidrio. El valor del $\mathrm{pH}$, se articula con la actividad metabólica de las bacterias y puede favorecer un determinado grupo en relación con el otro y ello puede ser explicado, debido a que el tratamiento 2 aportó un $33 \%$ más de la mezcla de clavo y de canela, además el contenido de azúcar influye considerablemente, puesto que provoca una saturación de las enzimas que degradan el sustrato y, por consiguiente, no existe fermentación (Gandy et al. 2008).

Investigaciones realizadas por García \& Pacheco-Delahaye (2010) sobre la evaluación de una bebida láctea instantánea a base de harina de arracacha, reportaron que durante el almacenamiento, a temperatura ambiente, la bebida no tuvo variación del contenido de humedad $(3,30-3,31 \%)$ y de $\mathrm{pH}$ $(6,6)$. Púa et al. (2011) reportaron valores similares en cuanto al $\mathrm{pH}(6,6)$, pero mayor acidez $(1,11 \%)$; este $\mathrm{pH}$ guarda relación con el inicial de la leche, el cual, es un buen indicador de la estabilidad del producto, además, la acidez hace relación al contenido de ácido láctico, presente en la bebida. Por su parte, Miranda et al. (2014) reportaron valores de $\mathrm{pH}$ mayores a estos estudios de 4,36 y acidez de 0,63 , para una bebida láctea, envasada en empaque de vidrio.

Haciendo énfasis en la acidez, la muestra control y T1 no reportaron diferencias estadísticas durante todos los días analizados; no obstante, el tratamiento 3 a los días 0 y 4 mostraron ser diferentes. Se puede establecer que la acidez es inversamente proporcional al $\mathrm{pH}$, observándose que aumenta significativamente durante el almacenamiento refrigerado. Este hecho puede ser explicado por el desdoblamiento de la lactosa en ácido láctico, por acción de las bacterias lácticas o por la actividad de $\beta$-galactosidasa, que conservan su actividad, a temperaturas de $0-5^{\circ} \mathrm{C}$ y como resultado de la acumulación de ácido acético, acetaldehído, ácido fórmico y ácido láctico (Oberman \& Libudzisz, 1988).

También, investigadores como Londoño et al. (2008), han afirmado que la acidez de una bebida láctea durante el almacenamiento puede ocurrir, debido a la producción de peróxi-
Tabla 2. Características químicas de los tratamientos de chicheme.

\section{Control}

\begin{tabular}{|c|c|c|c|}
\hline Parámetros & Días & Plástico & Vidrio \\
\hline \multirow{3}{*}{$p H$} & 0 & $6,38 \pm 0,75^{\mathrm{a}}$ & $6,70 \pm 0,05^{\mathrm{b}}$ \\
\cline { 2 - 4 } & 4 & $6,35 \pm 0,27^{\mathrm{a}}$ & $6,35 \pm 0,67^{\mathrm{a}}$ \\
\cline { 2 - 4 } & 7 & $6,31 \pm 0,67^{\mathrm{a}}$ & $6,34 \pm 0,31^{\mathrm{a}}$ \\
\hline \multirow{4}{*}{ Acidez } & 0 & $0,37 \pm 0,22^{\mathrm{a}}$ & $0,27 \pm 0,23^{\mathrm{b}}$ \\
\cline { 2 - 4 } & 4 & $0,38 \pm 0,12^{\mathrm{a}}$ & $0,29 \pm 0,63^{\mathrm{b}}$ \\
\cline { 2 - 4 } & 7 & $0,43 \pm 0,27^{\mathrm{a}}$ & $0,33 \pm 0,43^{\mathrm{b}}$ \\
\hline \multirow{3}{*}{ Brix } & 0 & $13,92 \pm 0,78^{\mathrm{a}}$ & $14,87 \pm 0,19^{\mathrm{b}}$ \\
\cline { 2 - 4 } & 4 & $12,85 \pm 0,36^{\mathrm{a}}$ & $14,77 \pm 0,53^{\mathrm{b}}$ \\
\cline { 2 - 4 } & 7 & $12,34 \pm 0,43^{\mathrm{a}}$ & $14,62 \pm 0,76^{\mathrm{b}}$ \\
\hline
\end{tabular}

T1

\begin{tabular}{|c|c|c|c|}
\hline Parámetros & Días & Plástico & Vidrio \\
\hline \multirow{3}{*}{$p H$} & 0 & $6,48 \pm 0,17^{\mathrm{a}}$ & $6,56 \pm 0,09^{\mathrm{b}}$ \\
\cline { 2 - 4 } & 4 & $6,47 \pm 0,12^{\mathrm{a}}$ & $6,56 \pm 0,65^{\mathrm{a}}$ \\
\cline { 2 - 4 } & 7 & $6,45 \pm 0,16^{\mathrm{a}}$ & $6,55 \pm 0,32^{\mathrm{a}}$ \\
\hline \multirow{3}{*}{ Acidez } & 0 & $0,33 \pm 0,21^{\mathrm{a}}$ & $0,26 \pm 0,03^{\mathrm{b}}$ \\
\cline { 2 - 4 } & 4 & $0,35 \pm 0,15^{\mathrm{a}}$ & $0,26 \pm 0,05^{\mathrm{b}}$ \\
\hline & 7 & $0,35 \pm 0,13^{\mathrm{a}}$ & $0,27 \pm 0,13^{\mathrm{b}}$ \\
\hline \multirow{3}{*}{ Brix } & 0 & $14,43 \pm 0,43^{\mathrm{a}}$ & $15,54 \pm 0,33^{\mathrm{b}}$ \\
\hline & 4 & $14,38 \pm 0,18^{\mathrm{a}}$ & $14,52 \pm 0,08^{\mathrm{b}}$ \\
\hline & 7 & $13,35 \pm 0,78^{\mathrm{a}}$ & $14,49 \pm 0,25^{\mathrm{b}}$ \\
\hline
\end{tabular}

T2

\begin{tabular}{|c|c|c|c|}
\hline Parámetros & Días & Plástico & Vidrio \\
\hline \multirow{3}{*}{$p H$} & 0 & $6,56 \pm 0,13^{\mathrm{a}}$ & $6,67 \pm 0,11^{\mathrm{b}}$ \\
\cline { 2 - 4 } & 4 & $6,52 \pm 0,13^{\mathrm{a}}$ & $6,65 \pm 0,16^{\mathrm{b}}$ \\
\cline { 2 - 4 } & 7 & $6,49 \pm 0,19^{\mathrm{a}}$ & $6,63 \pm 0,28^{\mathrm{b}}$ \\
\hline \multirow{3}{*}{ Acidez } & 0 & $0,20 \pm 0,32^{\mathrm{a}}$ & $0,20 \pm 0,07^{\mathrm{a}}$ \\
\cline { 2 - 4 } & 4 & $0,26 \pm 0,32^{\mathrm{b}}$ & $0,21 \pm 0,15^{\mathrm{b}}$ \\
\cline { 2 - 4 } & 7 & $0,26 \pm 0,09^{\mathrm{a}}$ & $0,25 \pm 0,19^{\mathrm{a}}$ \\
\hline \multirow{3}{*}{ Brix } & 0 & $16,03 \pm 0,27^{\mathrm{a}}$ & $16,84 \pm 0,25^{\mathrm{b}}$ \\
\cline { 2 - 4 } & 4 & $15,98 \pm 0,88^{\mathrm{a}}$ & $16,78 \pm 0,06^{\mathrm{b}}$ \\
\hline & 7 & $15,59 \pm 0,75^{\mathrm{a}}$ & $15,76 \pm 0,13^{\mathrm{a}}$ \\
\hline
\end{tabular}

T3

\begin{tabular}{|c|c|c|c|}
\hline Parámetros & Días & Plástico & Vidrio \\
\hline \multirow{3}{*}{$p H$} & 0 & $6,58 \pm 0,25^{\mathrm{a}}$ & $6,70 \pm 0,05^{\mathrm{a}}$ \\
\cline { 2 - 4 } & 4 & $6,53 \pm 0,45^{\mathrm{a}}$ & $6,68 \pm 0,32^{\mathrm{b}}$ \\
\cline { 2 - 4 } & 7 & $6,47 \pm 0,17^{\mathrm{a}}$ & $6,65 \pm 0,24^{\mathrm{b}}$ \\
\hline \multirow{3}{*}{ Acidez } & 0 & $0,19 \pm 0,07^{\mathrm{a}}$ & $0,19 \pm 0,12^{\mathrm{b}}$ \\
\cline { 2 - 4 } & 4 & $0,19 \pm 0,12^{\mathrm{a}}$ & $0,19 \pm 0,31^{\mathrm{a}}$ \\
\cline { 2 - 4 } & 7 & $0,23 \pm 0,14^{\mathrm{a}}$ & $0,20 \pm 0,09^{\mathrm{b}}$ \\
\hline \multirow{3}{*}{ Brix } & 0 & $17,62 \pm 0,16^{\mathrm{a}}$ & $17,03 \pm 0,35^{\mathrm{b}}$ \\
\cline { 2 - 4 } & 4 & $17,58 \pm 0,68^{\mathrm{a}}$ & $17,98 \pm 0,76^{\mathrm{a}}$ \\
\hline & 7 & $16,55 \pm 0,72^{\mathrm{a}}$ & $17,85 \pm 0,15^{\mathrm{b}}$ \\
\hline
\end{tabular}


do de hidrógeno, por algunos Lactobacillus, la composición del producto y el antagonismo entre microorganismos, por la producción de sustancias antimicrobianas. Además, el ácido láctico producido durante la fermentación contribuye a la desestabilización de la caseína, provocando la coagulación en el punto isoeléctrico (pH 4.6 a 4.7) (Demazzi et al. 2016).

Con respecto a los sólidos solubles, el tratamiento 1 y control mostraron diferencias con respecto al envase; sin embargo, la muestra T2 y T3 no tuvo diferencias estadísticas a los 7 y 4 días, respectivamente. Esta diferencia, se explica por la gran cantidad de azúcares fermentables que se encuentran en el maíz, sumados a la adición de azúcar, como sustrato para la fermentación, los cuales, llevan a la disminución de los sólidos solubles, de acuerdo a Spreer (1991); del mismo modo, se puede atribuir a la degradación de compuestos fenólicos con actividad antioxidante o a la proteólisis de la leche y los ácidos orgánicos (Sánchez et al. 2013).

Análisis microbiológico. En la tabla 3, se reportan los recuentos de UFC/mL de psicrótrofos, coliformes totales, co- liformes fecales, hongos y levaduras, BAL, Bacillus cereus y Staphylococcus aureus, para cada una de las formulaciones en envases de plástico y vidrio.

En el día 0 todas las muestras estaban dentro de los parámetros microbiológicos permitidos, de acuerdo a la NTC 5246 de 2004. Se observa que el día 7, el recuento de mohos y de levaduras para los tratamientos correspondientes a envase de vidrio y plástico, para las formulaciones T1 y T2, se encontraban por encima de los parámetros recomendados por la norma; además, se evidencia que el tratamiento que reportó una vida útil superior fue el envase de vidrio, con la concentración más alta de canela y de clavo.

Se puede evidenciar, que los mohos y las levaduras durante los cuatro días iníciales y en las formulaciones T1, T2 y T3 no tuvieron efecto inhibitorio sobre estos hongos; sin embargo, la formulación T3, en el día 7, reportó un 75\% de recuento, menos que T2. Las levaduras y BAL constituyen agentes potenciales de biocontrol de crecimiento de hongos, debido a su capacidad de crecer y de sobrevivir en productos ali-

Tabla 3. Resultados microbiológicos de vida útil para chicheme. Emp: Empaque, T: Tratamientos, P: Psicrotróficos, CT: Coliformes totales, CF: Coliformes fecales, M y L: Mohos y Levaduras, V: Vidrio, P: Plástico, F: Formulaciones; C: control.

\begin{tabular}{|c|c|c|c|c|c|c|c|c|c|}
\hline Día & Emp & T & P & CT & CF & M y L & BAL & B. cereus & S. aureus \\
\hline 0 & V & C & 280 & $<3$ & $<3$ & $<100$ & $<10$ & $<10$ & $<100$ \\
\hline 0 & V & T1 & 15 & $<3$ & $<3$ & $<100$ & $<10$ & $<10$ & $<100$ \\
\hline 0 & V & T2 & 200 & $<3$ & $<3$ & $<100$ & $<10$ & $<10$ & $<100$ \\
\hline 0 & V & T3 & $<10$ & $<3$ & $<3$ & $<100$ & $<10$ & $<10$ & $<100$ \\
\hline 0 & $\mathrm{P}$ & T1 & 500 & $<3$ & $<3$ & $<100$ & $<10$ & $<10$ & $<100$ \\
\hline 0 & $\mathrm{P}$ & $\mathrm{T} 2$ & 200 & $<3$ & $<3$ & $<100$ & $<10$ & $<10$ & $<100$ \\
\hline 0 & $\mathrm{P}$ & $\mathrm{T} 3$ & $<10$ & $<3$ & $<3$ & $<100$ & $<10$ & $<10$ & $<100$ \\
\hline 4 & $\mathrm{~V}$ & $\mathrm{C}$ & 490 & $<3$ & $<3$ & 180 & $<10$ & $<10$ & $<100$ \\
\hline 4 & $\mathrm{~V}$ & $\mathrm{~T} 1$ & 5 & $<3$ & $<3$ & $<100$ & $<10$ & $<10$ & $<100$ \\
\hline 4 & $\mathrm{~V}$ & $\mathrm{~T} 2$ & $<10$ & $<3$ & $<3$ & $<100$ & $<10$ & $<10$ & $<100$ \\
\hline 4 & $\mathrm{~V}$ & $\mathrm{~T} 3$ & $<10$ & $<3$ & $<3$ & $<100$ & $<10$ & $<10$ & $<100$ \\
\hline 4 & $\mathrm{P}$ & $\mathrm{T} 1$ & 20 & $<3$ & $<3$ & $<100$ & $<10$ & $<10$ & $<100$ \\
\hline 4 & $\mathrm{P}$ & $\mathrm{T} 2$ & $<10$ & $<3$ & $<3$ & $<100$ & $<10$ & $<10$ & $<100$ \\
\hline 4 & $\mathrm{P}$ & $\mathrm{T} 3$ & $<10$ & $<3$ & $<3$ & $<100$ & $<10$ & $<10$ & $<100$ \\
\hline 7 & $\mathrm{~V}$ & $\mathrm{~T} 1$ & $<10$ & $<3$ & $<3$ & 1100 & $<10$ & $<10$ & $<100$ \\
\hline 7 & $\mathrm{~V}$ & $\mathrm{~T} 2$ & $<10$ & $<3$ & $<3$ & 1700 & $<10$ & $<10$ & $<100$ \\
\hline 7 & $\mathrm{~V}$ & $\mathrm{~T} 3$ & $<10$ & $<3$ & $<3$ & 420 & $<10$ & $<100$ & $<100$ \\
\hline 7 & $\mathrm{P}$ & $\mathrm{T} 1$ & $<10$ & $<3$ & $<3$ & 1000 & $<10$ & $<10$ & $<100$ \\
\hline 7 & $\mathrm{P}$ & $\mathrm{T} 2$ & $<10$ & $<3$ & $<3$ & 530 & $<10$ & $<10$ & $<100$ \\
\hline 7 & $\mathrm{P}$ & $\mathrm{T} 3$ & $<10$ & $<3$ & $<3$ & 390 & $<10$ & $<10$ & $<100$ \\
\hline NTC 5246 & & & $5 * 10^{4}$ & 10 & 10 & 500 & - & $<10$ & - \\
\hline
\end{tabular}


menticios, bajo una amplia gama de condiciones ambientales, ya sea como complemento de cultivos iniciadores o de protección (Wilson \& Wisniewski, 1989; Dalié et al. 2010; Kapetanakou et al. 2012). También, Kempka et al. (2008) reportaron valores de $1 \times 10^{6} \mathrm{UFC} / \mathrm{mL}$ de células viables en una bebida láctea envasada en un empaque plástico, durante 22 días de almacenamiento refrigerado, además, el recuento de coliformes totales y fecales estuvieron ausentes; sin embargo, mohos y levaduras fueron de $4,9 \times 10^{3} \mathrm{UFC} / \mathrm{mL}$. Un factor a tener en cuenta con relación al elevado contenido de coliformes, en general, es la cadena de frío, el cual, es muy importante al evitar la proliferación de los microorganismos en este tipo de producto y, por consiguiente, el deterioro del mismo, ya que la temperatura de la bebida durante el proceso de pasteurización y de almacenamiento es uno de los factores importantes en el crecimiento bacteriano (Luigi et al. 2013).

En la tabla 3, se pudo comprobar que el tratamiento T1, en el día 4, aumentó el recuento de psicotrófilos, pero en el día 7, disminuyó considerablemente; esto pudo ser, debido a contaminación de la bebida durante el proceso de elaboración. Además, se debe tener en cuenta que algunos alimentos, como la leche, la actividad antimicrobiana del peróxido de hidrógeno en concentraciones no letales, se atribuye a su reacción con tiocianato, catalizada por la lactoperoxidasa. Los productos de esta reacción, como hipotiocianato y otras moléculas intermedias, pueden reducir el crecimiento de varios microorganismos indeseables (Schnürer \& Magnusson, 2005). El peróxido de hidrógeno, se produce por la mayoría de las bacterias acido lácticas y en presencia de oxígeno las BAL son incapaces de producir catalasa, por lo tanto, no pueden degradar el peróxido de hidrógeno, que después de la acumulación se oxida en la membrana de los lípidos y proteínas celulares de los organismos (Lindgren \& Dobrogosz, 1990; Dalié et al. 2010).

Análisis Sensorial. En la tabla 4, se observa el análisis sensorial realizado a la bebida chicheme. Se evidencia, que la muestra control tuvo diferencias significativas con los demás tratamientos en el sabor, color e impresión global. Para el sabor, color e impresión global de los tratamientos T1 y T2 no se observaron diferencias estadísticas, pero sí presentaron con la muestra T3. Con respecto al olor, este fue el único parámetro que no mostró diferencias con $\mathrm{T} 2$ y el control, pero sí con T3, es decir, a medida que aumentó la concentración de estas especias conservantes, el gusto de los catadores disminuyó en todas las variables evaluadas.

Tabla 4. Resultados del test de medias para las variables sabor, color, olor e impresión global de chicheme.

\begin{tabular}{|c|c|c|c|c|}
\hline Formulaciones & Sabor & Color & Olor & IG \\
\hline Control & $8,000^{\mathrm{a}}$ & $7,8000^{\mathrm{a}}$ & $7,5667^{\mathrm{a}}$ & $7,8000^{\mathrm{a}}$ \\
\hline T1 & $7,0750^{\mathrm{b}}$ & $7,2167^{\mathrm{b}}$ & $7,1917^{\text {ba }}$ & $7,0667^{\mathrm{b}}$ \\
\hline T2 & $7,2333^{\mathrm{b}}$ & $6,9417^{\mathrm{b}}$ & $6,9083^{\mathrm{b}}$ & $6,9333^{\mathrm{b}}$ \\
\hline T3 & $4,8333^{\mathrm{c}}$ & $5,0722^{\mathrm{c}}$ & $4,6667^{\mathrm{c}}$ & $4,6944^{\mathrm{c}}$ \\
\hline
\end{tabular}

Finalmente, se pudo comprobar que la formulación T3 con envase de vidrio fue la que tuvo un menor recuento de psicotróficos, mohos y levaduras. Además, a mayor concentración de clavo y de canela, el recuento de microorganismos fue menor. También, a medida que aumentaba la acidez en los envases de plástico y vidrio, el pH y el porcentaje de sólidos solubles disminuyó, debido al consumo de lactosa por parte de las BAL. Asimismo, el tratamiento térmico y la condición anaeróbica en que se encontraba la bebida produjo la estabilidad del pH y la acidez al final del periodo de almacenamiento, lo cual, podría estar relacionada con la inhibición de la actividad enzimática y disminución de la población bacteriana y, posiblemente, al agotamiento de la lactosa en los sustratos.
Conflictos de intereses: El manuscrito fue preparado y revisado con la participación de todos los autores, quienes declaramos que no existe conflicto de intereses que ponga en riesgo la validez de los resultados presentados.

\section{BIBLIOGRAFÍA}

1. ACEVEDO, D.; NAVARRO, M.; MONROY, L. 2013a. Composición química del aceite esencial de hojas de orégano (Origanum vulgare). Inf. Tecnol. (Chile). 24(4):43-48.

2. ACEVEDO, D.; NAVARRO, M.; MONTERO, P. 2013b. Composición química del aceite esencial de las hojas de Toronjil (Melissa officinalis L.). Inf. Tecnol. 24(4):49-54. 
3. ALZATE, L.M.; ARTEAGA, D.M.; JARAMILLO, Y. 2011. Evaluación de usos potenciales del desecho del fruto del algarrobo (Hymenaea courbarylL) -cáscara y semillas- como conservante natural para alimentos. Rev. Lasallista Invest. (Colombia). 8(1):90-95.

4. AOAC. 1990. Official Methods of Analysis of Official Analytical Chemists. 15th. Pub. by the A.O.A.C. Washington D.C.

5. ARORA, D.; KAUR, J. 1999. Antimicrobial activity of spices. Int. J. Antimicrobia Agents. (Netherlands). 12:257-262.

6. CARDOSO-UGARTE, G.A.; LÓPEZ-MALO, A.; SOSA, M.E. 2016. Chapter 38 - Cinnamon (Cinnamomum zeylanicum) Essential Oils. En: Preedy, V. Essential Oils in Food Preservation, Flavor and Safety. Academis Press. p.339.347.

7. DALIÉ, D.; DESCHAMPS, A.M.; RICHARD-FORGET, F. 2010. Lactic acid bacteria-Potential for control of mould growth and mycotoxins: A review. Food Control. (Netherlands). 21(4):370-380.

8. DEMAZZI, K.R.; JACOB, K.K.; FREITAS, A.A. 2016. Apectos sensoriais, físico-químicos e microbiológicos de iogurtes e bebida láctea espessados com amido de mandioca (Manihot esculenta Crantz). Braz. J. Food Res. 7(1):27-41.

9. GANDY, A.L.; SCHILLING, M.W.; COGGINS, P.C.; WHITE, C.H.; YOON, Y.; KAMADIA, V.V. 2008. The effect of pasteurization temperature on consumer acceptability, sensory characteristics, volatile compound composition, and shelf-life of fluid milk. J. Dairy Science. 91(5):1769-1777.

10. GARCÍA, A.; PACHECO-DELAHAYE, E. 2010. Evaluación de una bebida láctea instantánea a base de harina de arracacha (Arracacia xanthorrhiza) con la adición de ácido fólico. Rev. Chilena Nutrición. 37(4):480-492.

11. GENDE, L.; MAGGI, M.; BAREN, V.; LIRA, A.L.; BANDONI, A.; FRITZ, R.; EGUARAS, M. 2010. Antimicrobial and miticide activities of Eucalyptus globulus essential oils obtained from different Argentine regions. Spanish J. Agr. Res. (España). 8(3):642-650.

12. GOÑI, M.G.; ROURA, S.I.; PONCE, A.G.; MOREIRA, M.R. 2016. Essential Oils in Food Preservation, Flavor and Safety. Academic Press. UK. p.349-357.
13. KAPETANAKOU, A.E.; KOLLIAS, J.N.; DROSINOS, E.H.; SKANDAMIS, P.N. 2012. Inhibition of A. carbonarius growth and reduction of ochratoxin A by bacteria and yeast composites of technological importance in culture media and beverages. Int. J. FoodMicrobiol. (Netherlands). 152(3):91-99.

14. KEMPKA, A.P.; KRÜGER, R.L.; VALDUGA, E.; DI LUCCIO, M.; TREICHEL, H.; CANSIAN, R.; DE OLIVEIRA, D. 2008. Formulação de bebida láctea fermentada sabor pêssego utilizando substratos alternativos e cultura probiótica. Ciência Tecn. Alimentos. 28:170177.

15. KIM, Y.S.; LEE, S.H.; KIM, S.H.; JOO, Y.; BAHK, G.J. 2015. Investigation of the experience of foodborne illness and estimation of the incidence of foodborne disease in South Korea. Food Control.47:226-230.

16. LINDGREN, S.E.; DOBROGOSZ, W.J. 1990. Antagonistic activities of lactic acid bacteria in food and feed fermentations. FEMS Microbiol. Reviews. (UK). 7(12):149-163.

17. LONDOÑO, M.M.; SEPÚLVEDA, J.U.; HERNÁNDEZ, A.; PARRA, J.E. 2008. Bebida fermentada de suero de queso fresco inoculada con Lactobacillus casei. Rev. Facultad Nacional Agr. (Colombia). 61(1):44094421.

18. LUIGI, T.; ROJAS, L.; VALBUENA., O. 2013. Evaluación de la calidad higiénico-sanitaria de leche cruda y pasteurizada expendida en el estado Carabobo, Venezuela. Salus. (Venezuela). 17(1):25-33.

19. MIRANDA, M.O.; FONSECA, P.; PONCE, I.; CEDEÑO, C.; SAM, R.L.; MARTÍ, V.L. 2014. Elaboración de una bebida fermentada a partir del suero de leche que incorpora Lactobacillus acidophilus y Streptococcus thermophilus. Rev. Cubana Aliment. Nutr. 24(1):716.

20. MIRZOEVA, O.K.; GRISHANIN, R.N.; CALDER, P.C. 1997. Antimicrobial action of propolis and some of its components: the effects on growth, membrane potential and motility of bacteria. Microbiol. Research. 152(3):239-246.

21. NORMA TÉCNICA COLOMBIANA -NTC- 5246. Instituto Colombiano de Normas Técnicas y Certificación (Colombia). 2004. Productos lácteos. Bebida láctea con avena. Primera actualización, Bogotá, Colombia. 15p. 
22. NSOESIE, E.O.; KLUBERG, S.A.; BROWNSTEIN, J.S. 2014. Online reports of foodborne illness capture foods implicated in official foodborne outbreak reports. Preventive Medicine. (Estados Unidos).67:264-269.

23. OBERMAN, H.; LIBUDZISZ, Z. 1988. Fermented milks. Ed. Wood, B.J. Microbiology of Fermented Foods. (Glasgow, UK). p.308-345.

24. ÖZCAN, M.M.; ARSLAN, D. 2011. Antioxidant effect of essential oils of rosemary, clove and cinnamon on hazelnut and poppy oils. Food Chem. 129(1):171174.

25. PASTRANA, Y.I.; DURANGO, A.M.; DE PAULA, C.D.; ACEVEDO, D. 2015. Caracterización fisicoquímica, bromatológica y microbiológica de bebidas autóctonas de Córdoba, Colombia. Inf. Tecnol. 26(4):53-62.

26. PÚA, A.; CABALLER, L.; RIVERA, E. 2011. Evaluación de las características químicas, físicas y microbiológicas de una bebida láctea enriquecida. Ciencia y Tecnol. Aliment. 9(1):5-13.

27. ROCOURT, J. 2014. Public Health Measures: Foodborne Disease Outbreak Investigation. Encyclopedia of Food Safety. 4:89-97.

28. RODRÍGUEZ, E.N. 2011. Uso de agentes antimicrobianos naturales en la conservación de frutas y hortalizas. Ra Ximhai. (México). 7(1):153-170.

29. SÁNCHEZ, N.Y.; SEPÚLVEDA, J.U.; ROJANO, B.A. 2013. Desarrollo de una bebida láctea con extractos de curuba (Passiflora mollissima Bailey) como antioxidante natural. Biotecnol. Sector Agropec. Agroindustr. 11(1):164-173.
30. SCHNÜRER, J.; MAGNUSSON, J. 2005. Antifungal lactic acid bacteria as biopreservatives. Trends Food Sci. Technol. (Estados Unidos).16(1):70-78.

31. SHAN, L.C.; PANAGIOTOPOULOS, P.; REGAN, A.; DE BRÚN, A.; BARNETT, J.; WALL, P.; MCCONNON, A. 2014. Interactive Communication with the Public: Qualitative exploration of the use of social media by food and health organizations. J. Nutrit. Educat. Behavior. (Estados Unidos). 47(1):104-108.

32. SPREER, E. 1991. Lactología Industrial. Leche y Productos Lácteos. Editorial Acribia S.A (España). 617p.

33. TOYOFUKU, H. 2014. Food borne Diseases: Prevalence of food borne diseases in western pacific region. Encyclopedia of Food Safety. 1:312-322.

34. VARGAS, R.D.; TORRESCANO, G.R.; SÁNCHEZ, A. 2013. El propóleos: conservador potencial para la industria alimentaria. Interciencia. (Venezuela). 38(10):705-711.

35. WILSON, C.L.; WISNIEWSKI, M.E. 1989. Biological control of postharvest diseases of fruits and vegetables: An emerging technology. Ann. Rev. Phytopathol. (Estados(nnidos). 27(1):425-441.

36. YOUNG, I.; WADDELL, L.; SANCHEZ, J.; WILHELM, B.; MCEWEN, S.A.; RAJIĆ, A. 2014. The application of knowledge synthesis methods in agri-food public health: Recent advancements, challenges and opportunities. Preventive Vet. Med. (Netherlands). 113(4):339-355.

Recibido: Julio 9 de 2015

Aceptado: Septiembre 26 de 2016

Cómo citar:

Acevedo, D.; Pastrana, Y.; Durango, A. 2016. Estabilidad de chicheme procedente del departamento de Córdoba, Colombia. Rev. U.D.C.A Act. \& Div. Cient. 19(2): 395-402. 